\title{
Editorial: Becoming Part of our Team
}

\author{
Narciso Cerpa \\ Universidad de Talca, Faculty of Engineering, Curicó, Chile, ncerpa@utalca.cl \\ Editor-in-Chief, JTAER \\ September 2020
}

\section{Call for Team Members}

We have a few vacancies in the Journal of Theoretical and Applied Electronic Commerce Research (JTAER) starting in 2020. If you are interested in contributing to our journal and credentials in the electronic commerce field and would like to serve on the JTAER team in any of the roles described below, please contact the Editor-in-Chief Narciso Cerpa at ncerpa@utalca.cl. In all the roles we seek team members from diverse backgrounds, such as Computer Science, Information Systems, Business, Law, and the Social Science disciplines among others.

\section{Referee Role}

We are seeking for responsible academics or practitioners willing to contribute to the development of research in their area of expertise within electronic commerce. The main role of the referee will be to decide whether or not an article makes a sufficient contribution to the specific field of research. They will evaluate the quality of work undertaken by other researchers highlighting the strengths and weaknesses of the work, and ensuring the rigor of the research before it is widely disseminated through a journal publication. Providing your time to review papers keep you up to date with the latest developments in your area of research as well as providing you with exposure to cutting edge research methods. We are seeking for referees that are willing to achieve excellence in their aim of providing well justified evaluations and quality feedback to authors. Achieving excellence as a referee over a few years may also be the key to a future role in JTAER as an Editorial Board member. For more information on what is expected of a paper manuscript submission and the role of a reviewer please see [1], [2].

\section{Editorial Board Member Role}

The basic responsibilities of the Editorial Board membership include contributing to defining the strategic direction, policies and procedures for the journal, reviewing papers, organizing special issues, attracting quality papers, suggesting other Editorial Board members who are team players, proposing and attracting good reviewers, among others. The committee seeks individuals who are considered research leaders in their discipline of expertise. The committee seeks individuals who are considered high quality researchers and internationally well-known scholars in their research discipline. A good contribution as an Editorial Board member over a few years may also be the key to a future role on JTAER as a Co-Editor.

\section{Co-Editor Role}

The Journal of Theoretical and Applied Electronic Commerce Research is also seeking qualified candidates for CoEditor positions available in the Journal. The main responsibility of the Co-Editor role is to contribute to the screening process of submitted papers. The screening process of manuscripts is based on the JTAER quality standards (clarity of writing, adequate paper structure, theoretical and practical contribution, originality, theoretical foundations, and sound methodology) [2]. This is the first step (and sometimes the last step) in the review process. Additional responsibilities of the Co-Editor are developing journal strategies, setting policies and procedures, negotiating journal abstracting and indexing with organizations providing abstracting services, negotiating publication of special issues, attracting good quality papers for publication in the journal, finding and attracting good Editorial Board members and reviewers. The committee seeks individuals who are considered research leaders and internationally renowned scholars in their chosen discipline.

For nominations or questions regarding any of the roles available at the Journal of Theoretical and Applied Electronic Commerce Research, please email the Editor-in-Chief Narciso Cerpa (ncerpa@utalca.cl). Each candidate or nominee for the Reviewer, Editorial Board membership or Co-Editor role is requested to provide the following information:

1. Current CV that includes information about education, academic and administrative positions, publications, awards, professional affiliations and activities, and other relevant items.

2. Description of previous experience in a Reviewer, Editorial Board member or Co-Editor role with scholarly journals or other types of publications. 
We would like to encourage those researchers and practitioners that have not participated in these roles in the past due to time constraints or other factors, to consider their participation in JTAER now, and give their time and expertise to the research community of which they are well-known members.

\section{References}

[1] N. Cerpa, Editorial: Becoming a referee, Journal of Theoretical and Applied Electronic Commerce Research, vol. 2, no. 1, pp. I-III, 2007.

[2] N. Cerpa and M. Pejić Bach, Editorial: What is expected of your paper manuscript submission?, Journal of Theoretical and Applied Electronic Commerce Research, vol. 14, no. 2, pp. I-III, 2019. 